\title{
Uncertainty in the modeling of spatial big data on a pattern of bushfires holes
}

\author{
A. Stein, V.A. Tolpekin \\ Faculty of Geo-Information Science and Earth Observation (ITC), University of Twente, \\ PO Box 217, 7500 AE Enschede, the Netherlands
}




\section{Abstract}

This paper focuses on the presence of vegetation patches, called holes remaining after forest fires. Holes

are of interest to explore because their vegetation is affected by severe temperature stress nearby, while they can serve as an agent to regenerate a forest after the burn. Further, it is interesting to know why holes emerge at all, while little if anything is known about their structure and distribution in space. A statistical analysis of their presence and abundance and a spatial statistical analysis to analyze their positions was done within four forest fire footprints. Fractal dimension of the holes was compared to that of the forest fire footprint, while remote sensing imagery was used to identify the NDVI of the patches before and after the fire. Results showed that the fractal dimension of the holes is lower than that of the forest fire footprint, and that the NDVI is slowly recovering to the original NDVI. Differences with the NDVI of the surrounding areas remain large. We concluded that patches of vegetation after a forest fire are interesting to study, providing clues of why unburned patches occur despite the fire presence nearby, how they can be characterized spatially and how the vegetation composition responds to such nearby fire.

\section{The Recommendations for Resource Managers}

Forest fires affect the forests, and have an effect on the population living within the forest and close to it. A forest fire commonly leaves behind a large number of unburnt vegetation patches. In this study we call them holes. These holes have been under severe heat and smoke pressure, but have similar tree species and forest structure as the original forest. They serve as the starting point to regenerate the forest. The primary implications for resource management are:

- A better understanding of where they are, and how they are composed may help to understand the behavior of a fire;

- Their characterization may help to better understand the relation between vegetation as a fuel for forest fire;

- Their biodiversity will improve the fire spread modeling of burns that are carried out for management of a forest stand.

Keywords

Forest fire; vegetation patches; hole; spatial variation; fractal dimension; remote sensing; NDVI 


\section{Introduction}

Forest fires are recurring natural disturbances (Pausas and Keeley, 2009). Their occurrence has been addressed at length in the scientific literature. In the spatial statistical literature we identify studies on the patterns of fires at various scale. For example, Turner (2009) studies the occurrence of bushfires in New Brinswick and Hering et al. (2009) in a river water management district, Wotton and Martell (2005) present a logistic regression model for single fires for Ontario, and Gupta et al. (2015) consider LIDAR information of a single fire.

Routinely collected data e.g. by satellites offer a rich source of information for relevant studies. Forest fire footprints are well recognizable from satellite sensors, in particular shortly after the fire. We can identify various sources for mapping the fire footprint. The first source would be visual observations and estimates of patches. Good examples are provided in Quintano et al. $(2010,2011)$, who also checked the boundaries of footprints with GPS observations. Typically, during classification they lead to errors of omission and commission caused by misclassification of burned areas as rocks, positional errors due to the presence of tree canopy and pre-fire burned areas as being caused by the present fire. Recently, with the advent of modern remote sensing techniques, satellite derived burned area products have been made available. Excamples are the Copernicus burnt area surface (Copernicus 2018) and the The European Forest Fire Information System (EFFIS 2018). Hally et al. (2016) and Mitchell et al. (2016) studied the early detection of forest fires, whereas Wallace et al. (2015) focused on relating the satellite information to hazard rate detection.

Integrating information from forest fires, however, is still a challenge. Spatial statistics is suited to make this step, as it allows to handle such a big spatial data by summarizing the data and express measures of variation and uncertainty. It requires detailed information, and objects as generated by point observations (Baddeley et al. 2016). In particular, it is able to develop models to relate the observed information from patterns to information that is relevant for the stakeholders. Typical issues concern the prediction of forest fire behavior with all its uncertainties, given wind speed and direction, vegetation and elevation differences, the estimation of the size of the fire footprint and mapping the pattern of their occurrences in larger areas. Quintano et al. $(2010,2011)$ estimated the size of fire footprints, including the uncertainties using satellite information, Umamaheshwaran et al. (2007) and Penman et al. (2013) presented models to predict and simulate the behavior of a fire in space and time and Nangendo et al. (2005) focused on long-term ecological consequences of fires. In the literature, two main types of fire are distinguished: bushfires, also called scrubs, being an uncontrolled fire in the bush; and burns, being a prescribed or planned burn fire, i.e. a fire started intentionally to reduce the fuel load, which at the same time aims to manage the landscape with low-intensity fires (Duff and Tolhurst 2013).

Somewhat surprisingly, because of their unique characteristics, rather limited attention has been given to patches of vegetation that remain after a fire (see however Penman et al. 2007; Farmer et al. 2011). In fact, many fire footprints contain such holes. The holes may consist of water bodies, vegetation patches that are not burned or areas without vegetation or with vegetation that does not burn. The causes for holes are also related to fire severity and intensity. The pattern of holes as identified for single fire footprints then has a patchy nature. The number of patches and the degree of patchiness is often higher than expected. Holes are common, and mapping burned areas usually does not pick up the on-ground spatial complexity and fragmentation of burn/non-burn areas.

We can identify various causes for holes: 
- Fire suppression activities protecting an asset: firefighting sky cranes dumping water, bulldozers creating control lines. These may generate patches, as the forest around the patches may burn.

- Natural breaks, as a combination of the fuel load and moisture. Typical examples are roads, or natural open spaces, like gardens and water bodies.

- Sudden wind direction changes may also lead to patchiness, as the fire fronts can be irregular and a sudden change in wind direction may lead to patches that are not affected by the fire.

Holes in fires are of several interests. First, it is interesting to explore why holes emerge at all. Second, the holes can serve as an agent to regenerate a forest after the burn. Third, holes have been under a severe temperature stress and their composition is most likely affected by the fire around. Finally, little if anything is known about their structure and distribution in space. For all these reasons we aim at a statistical characterization of holes that remain within a bushfire footprint. We will consider homogeneous and non-homogeneous modelling of the holes, compare the bush fires and the burns in terms of the spatial characterization of the patterns of holes left behind after a fire. As concerns terminology we fill follow Keeley (2009).

\section{The dataset}

For this study we had the Victoria bushfire database to our disposal which contained the bushfires observed and registered from 1939 until 2016 (Victoria 2018). For example, a recent year, 2014 (Figure 1) had 6195 fire footprints of which 324 contained holes. 


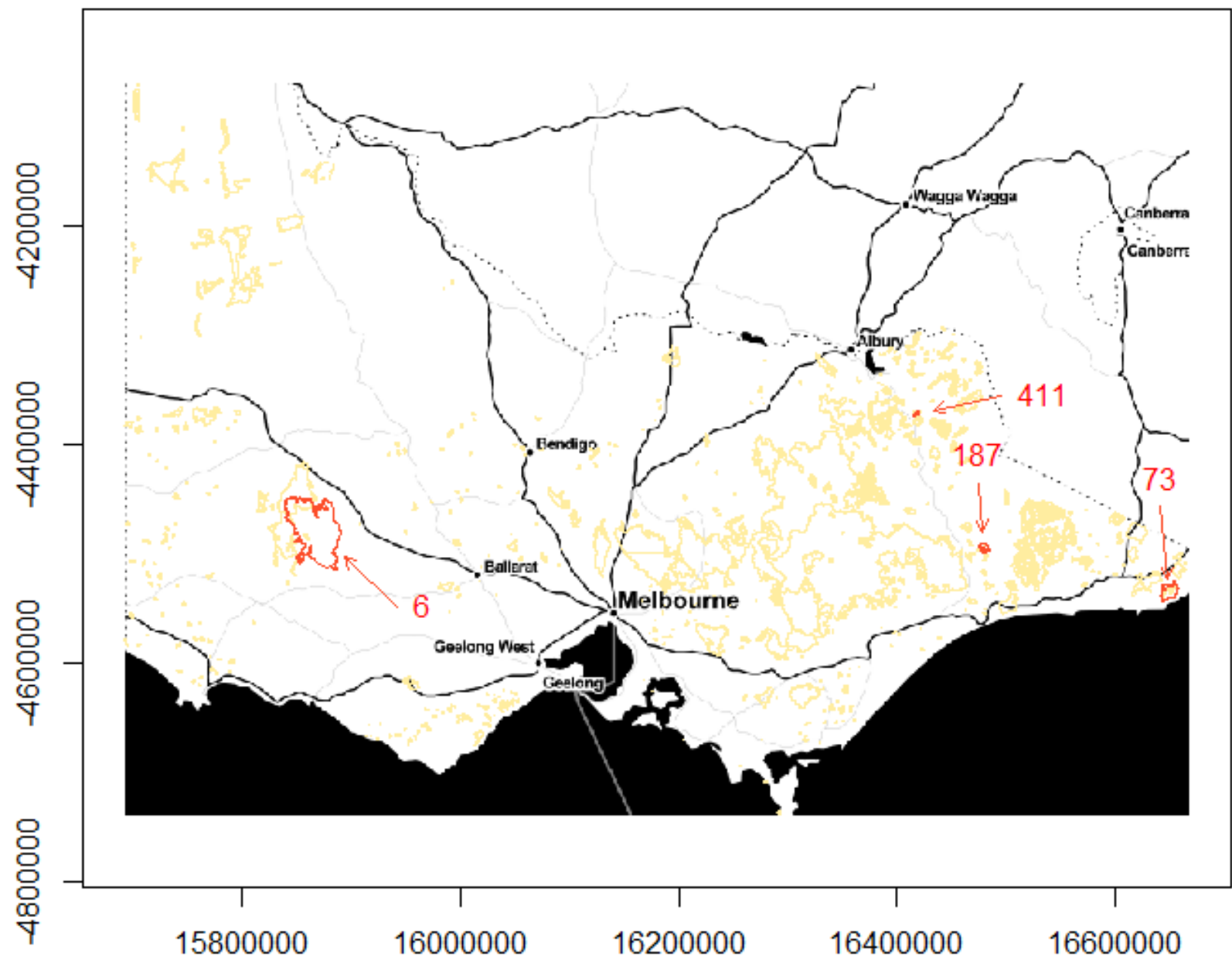

Figure 1: Bushfires and controlled burns with holes (not shown) between 2006 and 2016 (in yellow), from the Victoria bushfire database. In red: fires selected for this study. Map source: (C Stamen Design, under a Creative Commons Attribution (CC BY 3.0) license. Map tiles by Stamen Design, under CC BY 3.0. Data by OpenStreetMap, under ODbL

From this dataset we extracted four fires: bushfires no. 6 and no. 187, and burns no. 73 and 411 (Figure 2). The reason to select these were that the fires were of a relatively large size and contained a large amount of holes. Unless otherwise stated, we concentrate on these four fires. 


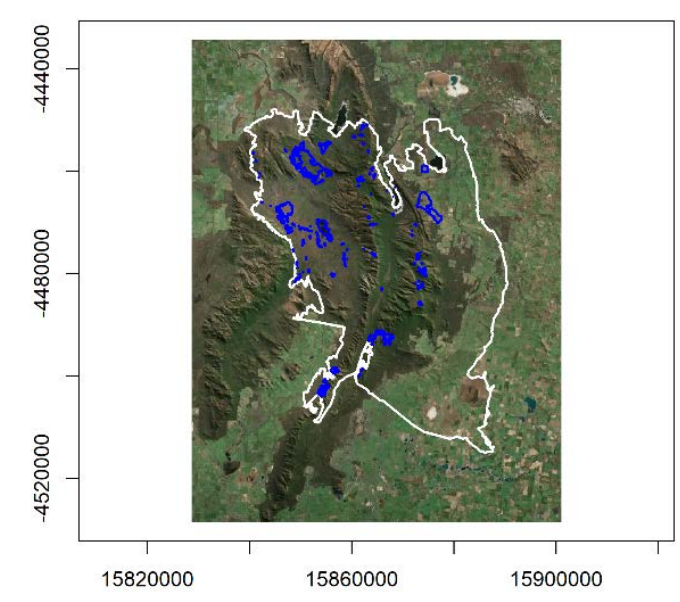

a)

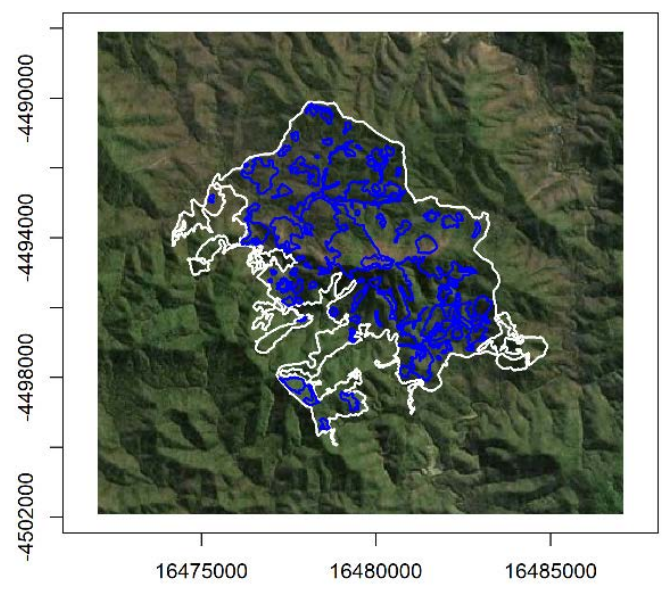

c)

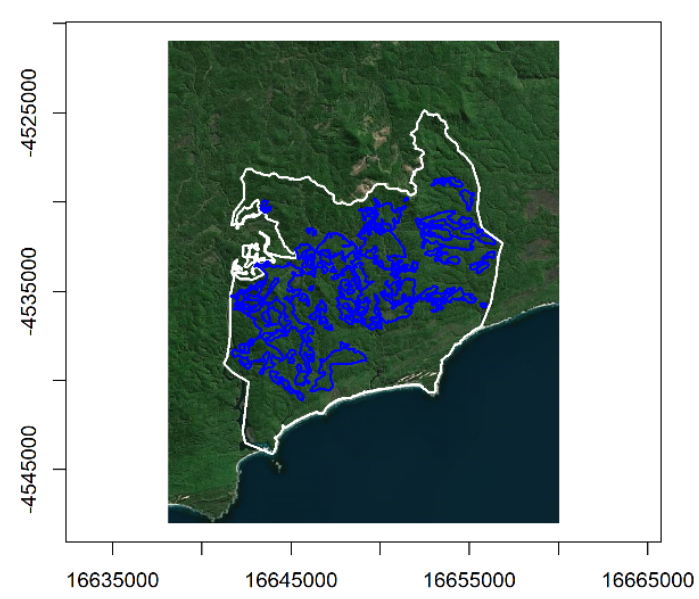

b)

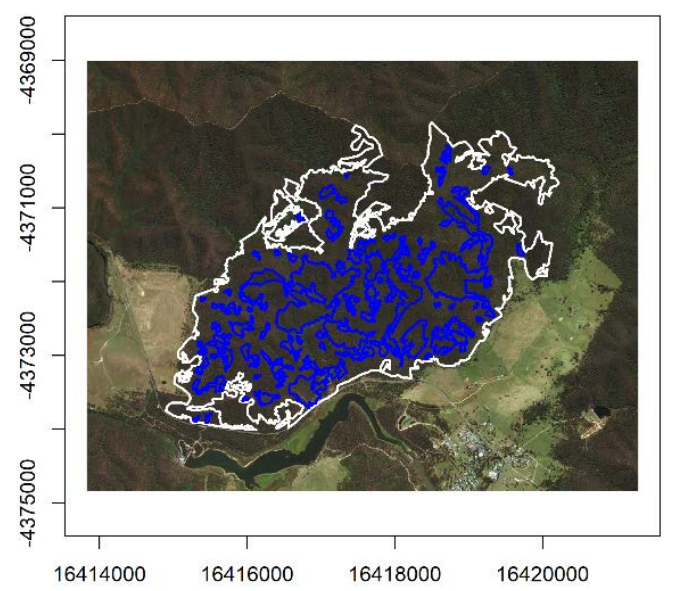

d)

Figure 2: selected fires from the Victoria database a)6, b) 73, c) 187 and d) 411: a) and c) are bushfires whereas b) and d) are burns. The white line indicates the footprint, holes are shown in blue. Bing Maps product screen shot(s) reprinted with permission from Microsoft Corporation

The development of vegetation vigor.

Remote sensing images are useful to monitor the development of the vegetation around a burn. We focus on the Normalized Difference vegetation Index (NDVI) defined as the ratio of difference of the red 
and the near infrared band and the sum of those two bands. It is closely related to the vigor of vegetation. The fire history data from 2003 to current is mainly created from thermal linescan imagery. The holes in the data tend to be unburnt, as 'current burnt area' was mapped and anything that wasn't burnt was left blank. Therefore, holes in the data may represent where the fire was patchy or a mosaic and did not burn the area completely. We consider Landsat ETM images of one particular fire, footprint number 6, representing a burn at 20 January 2006 (Figure 3). We had an image three weeks before the fire (29 December 2005), one image three weeks after the fire (15 February 2006) and one image six months after the fire (14 June 2006). The vegetative vigor shortly before a fire and may indicate the vulnerability of a forest area of being burned, whereas images after the fire show the regeneration of the area.

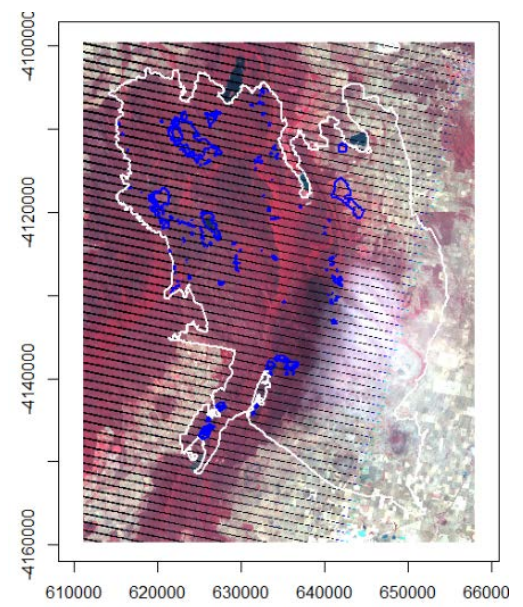

a)

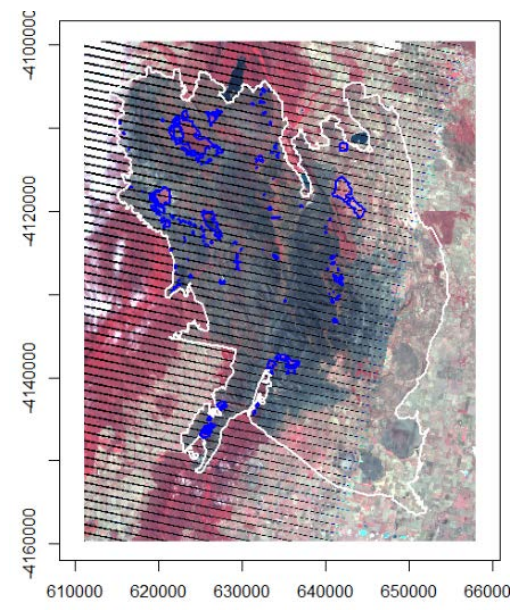

b)

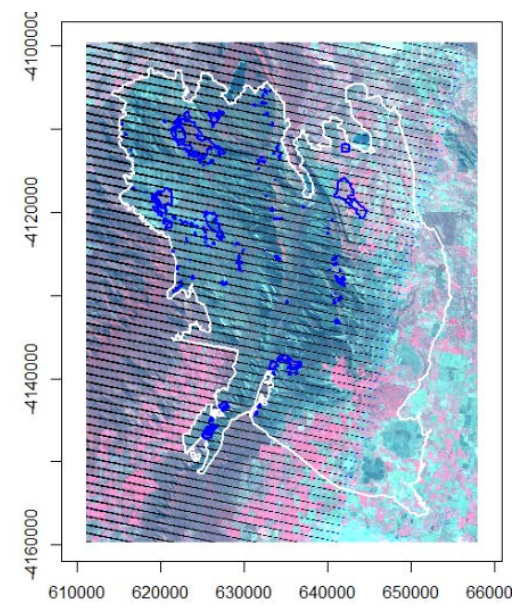

c)

Figure 3: Landsat ETM images covering the area of bushfire 6 from Figure 2a from 20 January 2006. a) 29 December 2005, b) 15 February 2006, c) 14 June 2006, respectively. Band combination is R:G:B=4:3:2. White polygon: fire extent area. Blue polygons indicate holes. Data affected by striping are excluded from the analysis.

\section{Methodology}

\subsection{Descriptive statistics}

First, we analyzed the number of holes in relation to other aspects of the fire. For analyzed the size of the fires, the sizes of the holes, and the position of the holes with respect to the center. The center serves as one particular point without any physical meaning - in case of stationarity, any other point could have taken as well, but in absence of other data, it seems a logical choice. For this, we used $d=$ the distance between hole and fire center and $R=$ radius of circle with same center and area as fire extent (Fig. 3). 


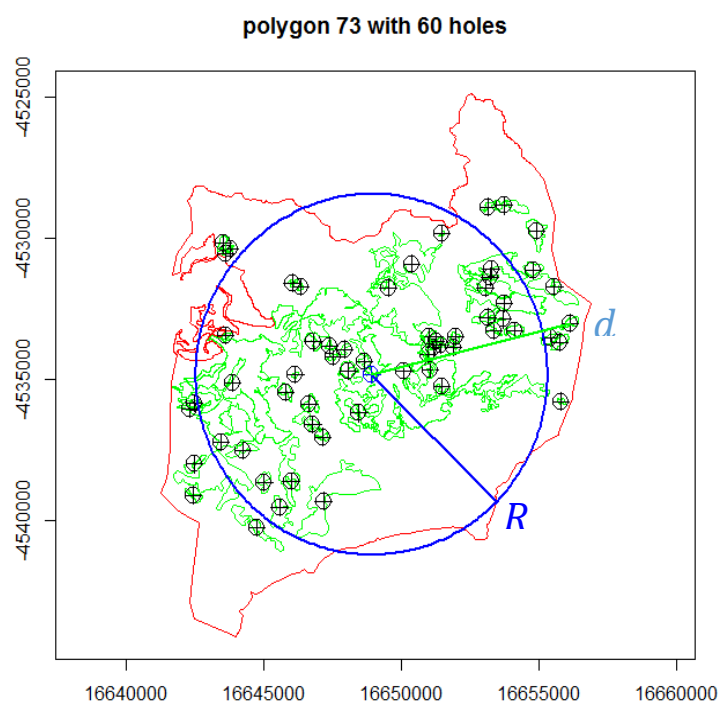

Figure 4: relation between $d=$ the distance between hole and fire center and $R=$ radius of circle with same center and area as fire extent to measure the position of the holes with respect to the center.

Five distributions were fitted for the full database, excluding the fires with no holes:

- $\quad$ the Poisson distribution with parameter $\mu$ specifying both the expectation and the variance (a natural choice, as the variable represents counts);

- the negative binomial distribution with parameters $p$ for the probability of an event and $n$ for the number of events, with expectation equal to $n \cdot p$ and variance equal to $n \cdot p \cdot(1-p)$ (an obvious choice for positive values);

- the log-normal distribution with expectation $\mu$ and variance $\sigma^{2}$ (being the common distribution to model skewed data);

- the exponential distribution with cut-off parameter $\alpha$ and scale parameter $\lambda$ and expectation equal to $\alpha+1 / \lambda$ and variance to $\lambda^{-2}$ (adequate for positive values);

- $\quad$ the Neyman-A distribution with parameters $\lambda_{1}$ and $\lambda_{2}$, and expectations equal to $\lambda_{1} \cdot \lambda_{2}$ and variance to $\lambda_{1} \cdot \lambda_{2} \cdot\left(1+\lambda_{2}\right)$ (Anscombe, 1950; Massé and Theodorescu, 2005).

\subsection{Spatial distribution of the holes: Ripley's $K$ function}

Let $\lambda$ be the intensity of the holes, assumed to be constant. Then $2^{\text {nd }}$ order properties of spatial point patterns describe how the interaction or spatial dependence between holes varies through space. For the current study we use Ripley's $K$ function (Ripley, 1977; Baddeley et al., 2016), which is defined as

$$
K(r)=\lambda^{-1} \mathrm{E}[\text { No. holes } \leq r \text { of an arbitrary hole }]
$$

The theoretical value of $K(r)$ is known for several models: $K(r)=\pi r^{2}$ for a homogeneous distribution of the holes, $K(r)>\pi r^{2}$ for clustering and $K(r)<\pi r^{2}$ for regularly spaced holes. The inhomogeneous $K$ function $K_{\text {inh }}(r)$ is a direct generalization to nonstationary point processes. Suppose $x$ are the holes as a point process with non-constant intensity $\lambda(u)$ at each location $u . K_{i n h}(r)$ is the expected value, given that $u$ is a hole, of the sum of all terms $1 / \lambda\left(x_{j}\right)$ over all holes $x_{j}$ in the process separated from $u$ 
by a distance less than $r$. This reduces to the ordinary $K$ function if $\lambda(u)$ is constant. If $x$ is an inhomogeneous Poisson process with intensity function $\lambda(u)$, then $K_{\text {inh }}(r)=\pi r^{2}$.

To estimate the $K$ function, let $n$ be the number of holes, $A$ the area of the footprint and $r_{i}, j$ the distance between holes $x_{i}$ and $x_{j}$. Further, let $I_{r}\left(r_{i, j}\right)$ be the indicator function, i.e., $I_{r}\left(r_{i, j}\right)=1$ if $r_{i, j}<$ $r$ and $I_{r}\left(r_{i, j}\right)=0$ if $r_{i, j}>r$, and let $w_{i j}$ be the proportion if the circle located at holes $x_{i}$ and passing through hole $x_{j}$ that lies within $A$. Then the estimator equals

$$
\widehat{K}(r)=n^{-2}|A| \sum_{j} \sum_{i \neq j} w_{i, j}^{-1} I_{r}\left(r_{i, j}\right)
$$

Edge corrections are used to correct bias in the estimation of $K_{\text {inh }}(r)$. There are several ways to do an edge correction.

The edge-corrected estimate of $K_{\text {inh }}(r)$ is of the form

$$
K_{\text {inh }}(r)=\sum_{i} \sum_{j} 1\left(d_{i, j} \leq r\right) \frac{e\left(x_{i}, x_{j}, r\right)}{\lambda\left(x_{i}\right) \lambda\left(x_{j}\right)}
$$

where $d_{i, j}$ is the distance between holes $x_{i}$ and $x_{j}$, and $e\left(x_{i}, x_{j}, r\right)$ is an edge correction factor.

For example, for the so-called 'border' correction we take

$$
e\left(x_{i}, x_{j}, r\right)=\frac{1\left(b_{i}>r\right)}{\sum_{j} 1\left(b_{j}>r\right) / \lambda\left(x_{j}\right)}
$$

where $b_{i}$ is the distance from $x_{i}$ to the boundary of the window.

To properly apply Ripley's K-function, in principle only two holes are sufficient. A dataset of more (e.g. 10) points would allow the construction of $95 \%$ prediction intervals for the K-function from a homogeneous process with a mean of 10 points. To be detectably different from a Poisson process, a dataset of 10 points would need a K-function that goes outside these intervals somewhere.

\subsection{The fractal dimension}

Of generic interest is the irregularity of the boundaries of the holes. Let $n$ be the number of points of a polygon and let $r$ be the length of the line that connects points on the polygon. Then the fractal dimension equals

$$
d_{f}=\frac{\ln n}{\ln r}
$$

\section{Results}

\subsection{Descriptive statistics}

The number of holes for the full database (excluding 0 holes) is given in Figure 5. Clearly, the Neyman-A distribution with parameters $\lambda_{1}=1, \lambda_{2}=0.5$ provided the most adequate fit well representing the large density of fires with one hole. 


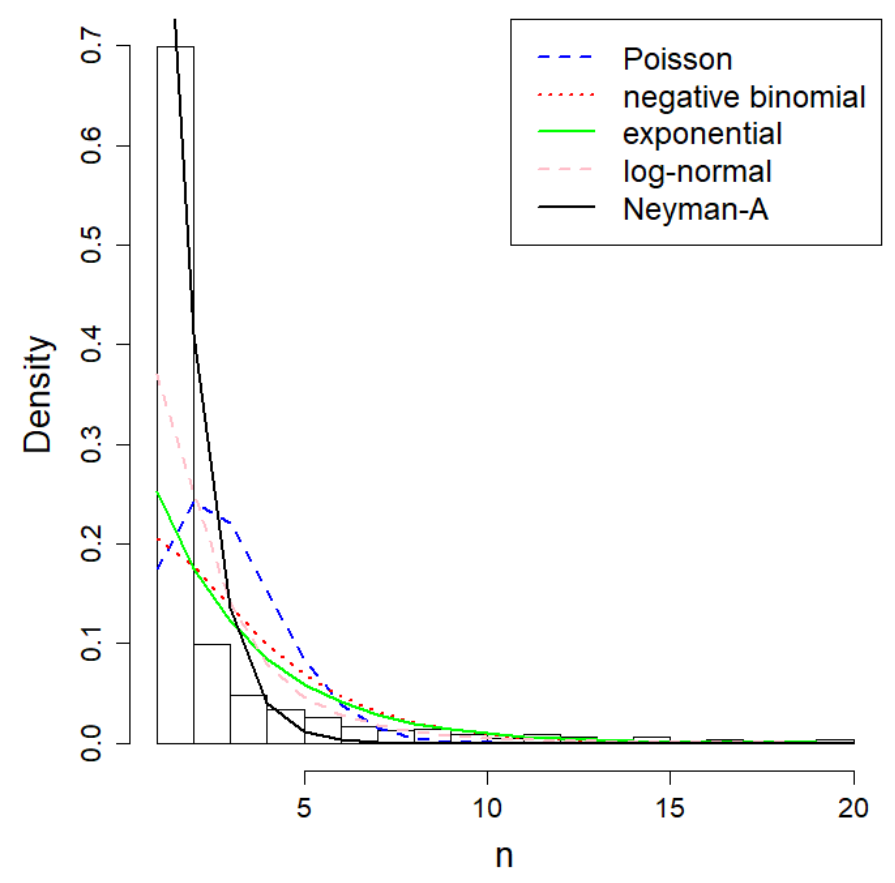

Figure 5: Distribution of the number of holes for all the fires in the database.

Figure 6a shows the descriptive statistics for all the fires in the database. We first note that the log of the sizes of the holes shows a symmetric distribution, with a mode approximately equal to a mean $\log$ (hole area) of 12, corresponding to $163000 \mathrm{~m}^{2}$. Both higher and lower outliers exist, keeping the distribution somewhat remote from a Normal distribution. Next, figure $6 \mathrm{~b}$ shows the relation between the number of holes and the size of the fires for the full dataset. We notice that there is an increase in the number of holes with increasing area. As large fires are likely have more holes than small fires, because of problems in the detectability of small holes in small fires, we see that also for relatively small fires, the number of holes can be large. However, a strong statistical relation could not be found. Figure $6 c$ shows that the ratio of the area of the hole and the magnitude of the outer extent peaks is relatively close to 0 , i.e. at 0.01 . Finally, Figure $6 d$ shows that the median of $d / R$ equals 0.792 , i.e., the holes are away from the middle of the footprint. We also found that the area of the hole/outer extent equals 0.00045 , a very small number, i.e. there are many small holes. The median of the $\log$ (hole area) equals 10.0, corresponding to $22130 \mathrm{~m}^{2}$ : hence the median size is slightly above 2 ha. 


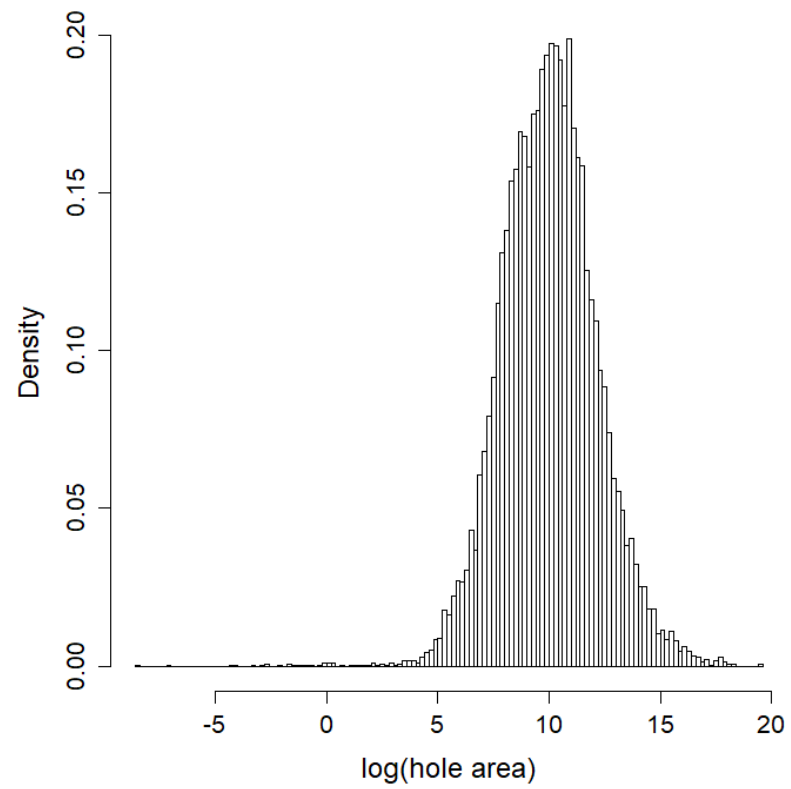

a)

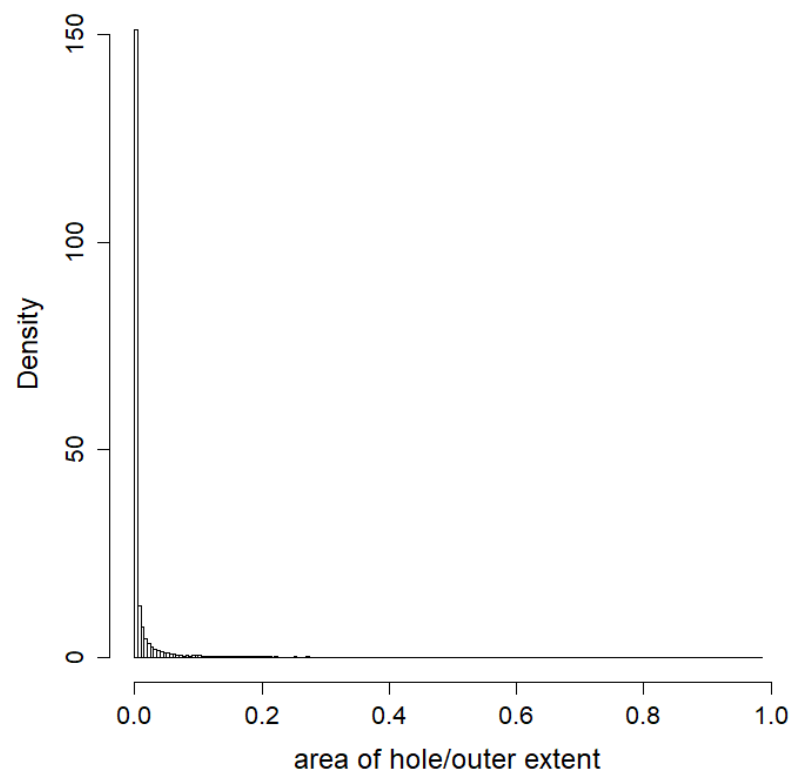

c)

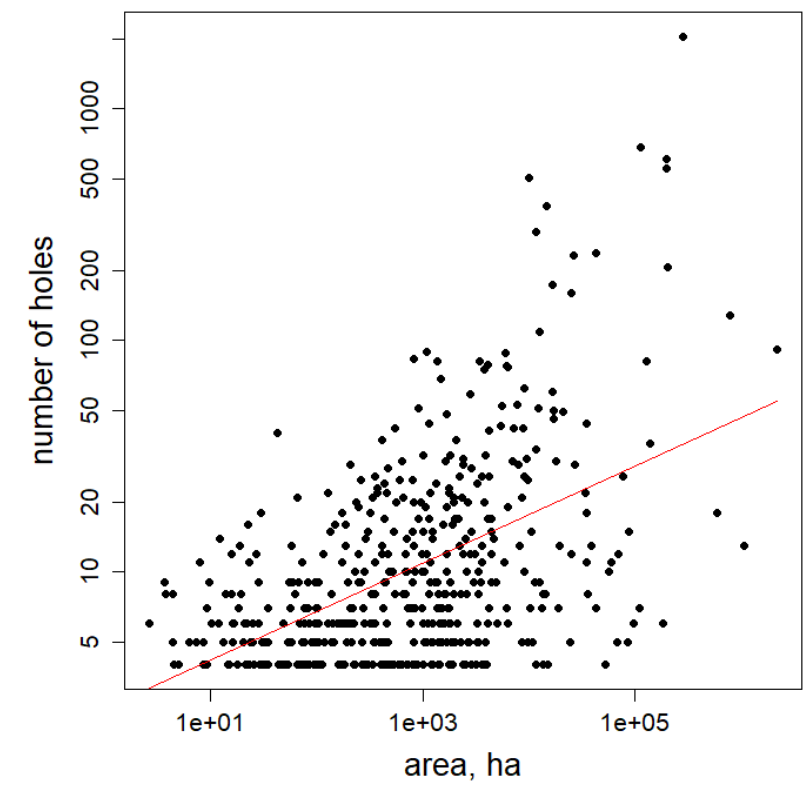

b)

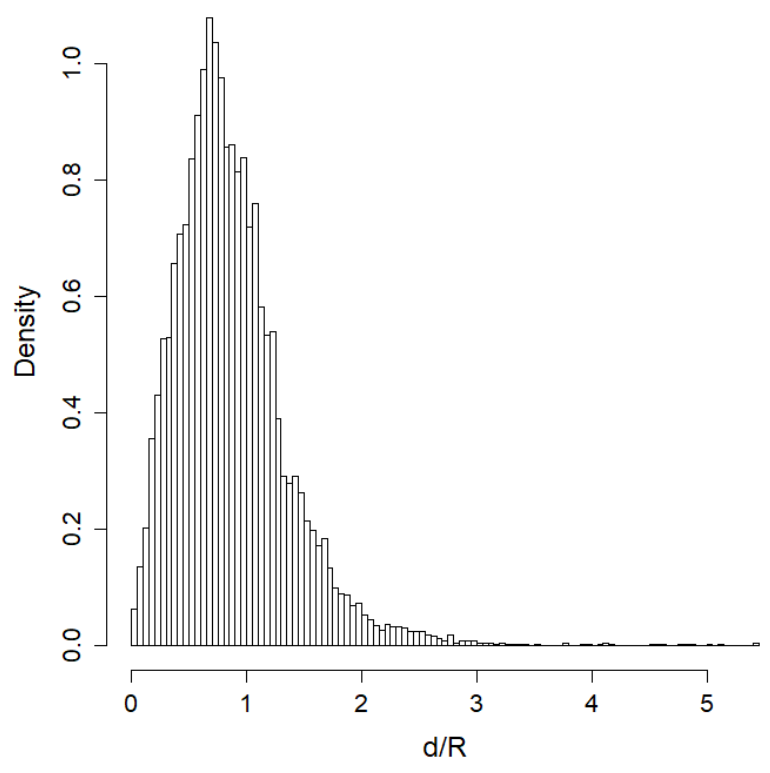

d)

Figure 6: Descriptive statistics for the bushfires in Victoria between 1939 and 2016: the density of the $\log$ (hole area) with area expressed in $\mathrm{m}^{2}(\mathrm{a})$, relation between the area of the fire and the number of holes(b), the density of the ratio between the area of the hole and the size of the outer extent (c) and the $\mathrm{d} / \mathrm{R}$ ratio (d). Line in $\mathrm{b}$ ) shows the linear regression, resulting in $R^{2}=0.252$. 


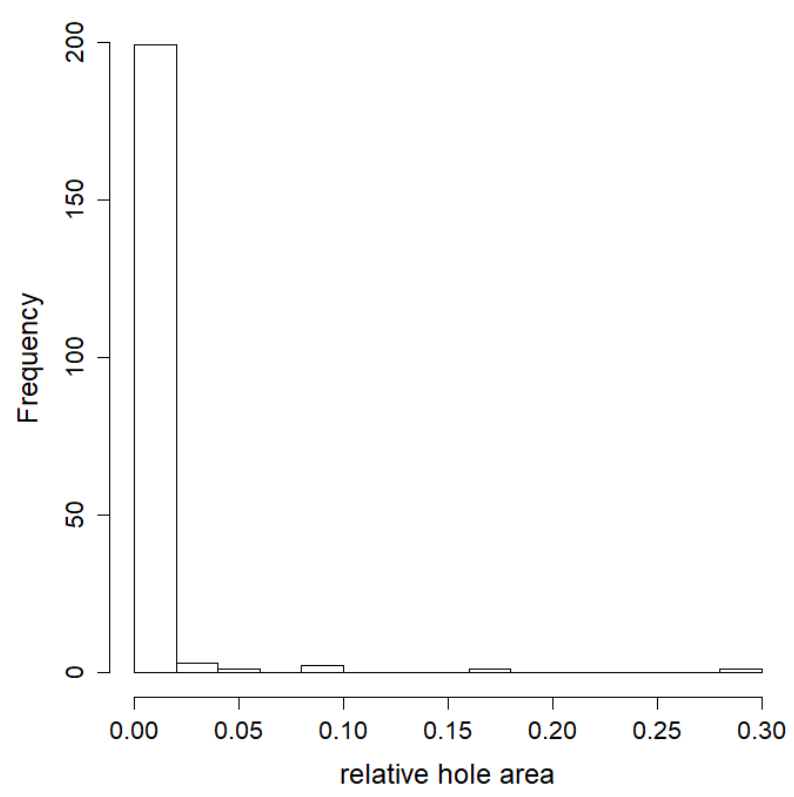

a)

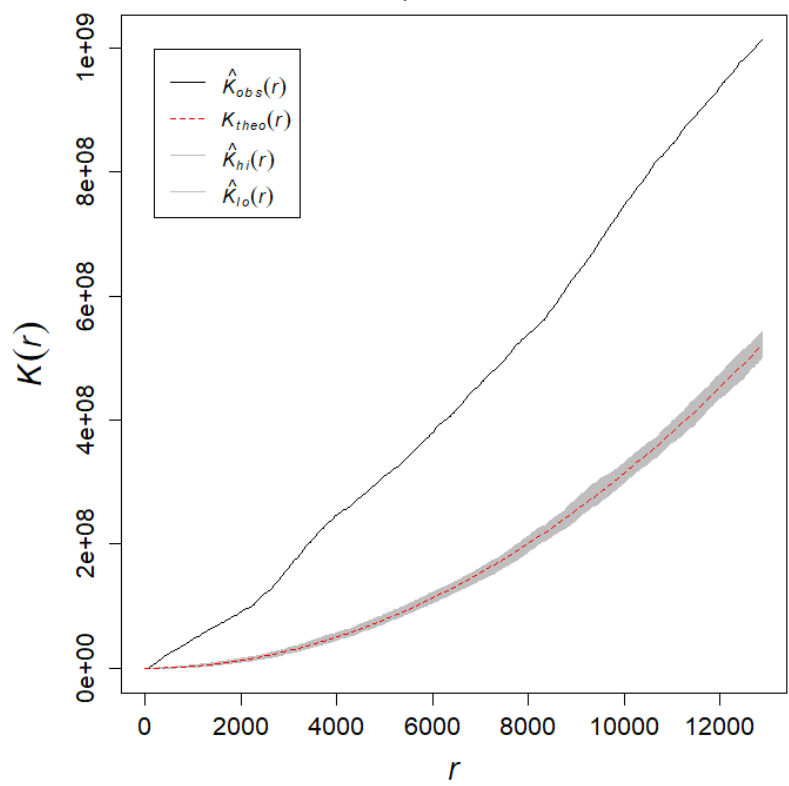

c)

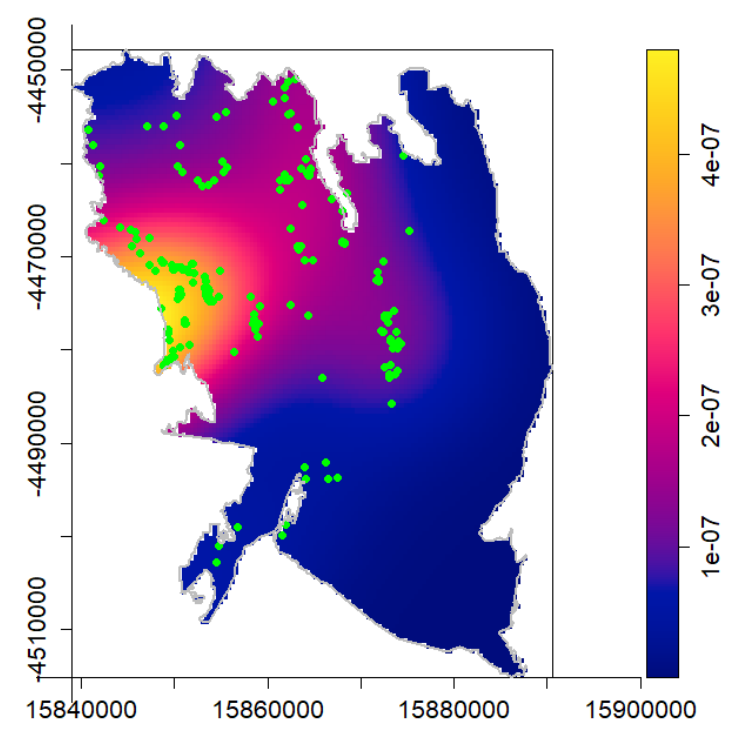

b)

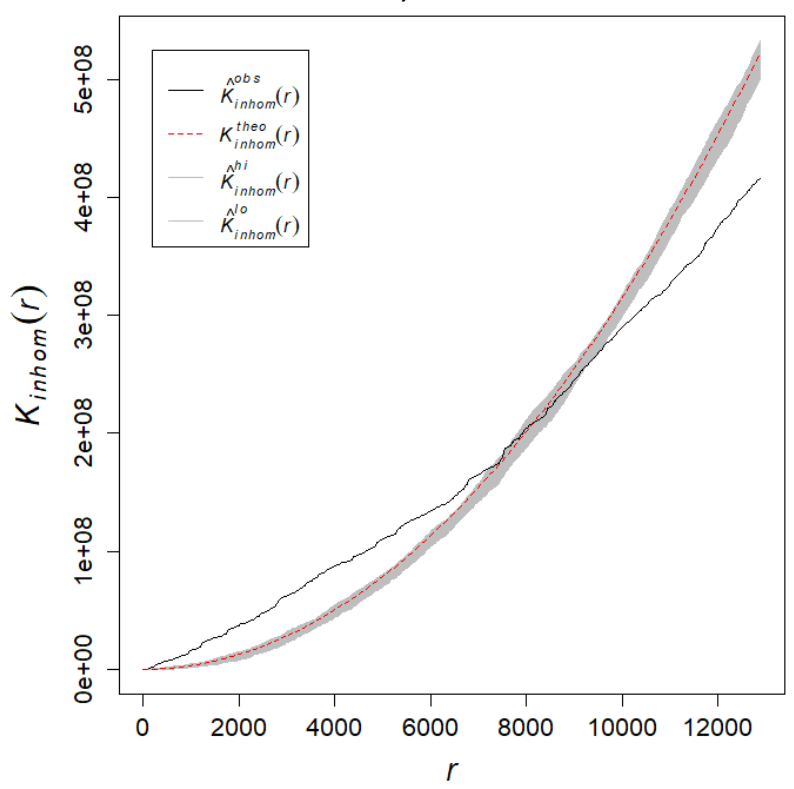

d)

Figure 7: The spatial distribution of the holes within the bushfire no. 6 footprint. The density of the holes (a), the pattern of the holes and their intensity (b), a comparison of the observed $K$ function (black line) with the theoretical CSR density plot, including confidence bounds expressed by $\widehat{K}_{l o}$ and $\widehat{K}_{h i}$ (c), and a comparison between the observed $K$ function and the non-homogeneous $K$ function (d). 


\subsection{The spatial distribution}

In order to study individual fire behavior, we focus on fire 6, being a bushfire. The relative hole area is clearly peaked, with small holes much more abundant than larger ones. The density shows a clear spatial inhomogeneity, with a high intensity in the western part of the area and a lower density of holes at the eastern and southern part of the footprints. When estimating Ripley's $K$ function, we notice that the assumption of homogeneity results into a clustering. Taking the non-homogeneous $K$ function, we see that there is clustering for small distances, e.g. up to $7 \mathrm{~km}$ with the estimated $K$ function above the $95 \%$ confidence intervals, and regularity for larger distances, e.g. $>9 \mathrm{~km}$ with the estimated $K$ function below the $95 \%$ confidence interval. This is also revealed by the spatial intensity pattern, where we see regularly spaced clusters. This case of fire no. 6 is somewhat different from the other three fires as reported in the supplementary materials: both the second bushfire we analyzed and the two burns we analyzed all showed a random pattern of holes within the fire footprint, if we model them with a homogeneous or an inhomogeneous $K$ function. For the four fires we thus notice that some indicate inhomogeneity in the pattern of holes, but this is not commonly observed. There also does not seem to be a clear difference in spatial patterns of holes between burns and bushfires.

\subsection{Fractal dimensions}

We once more first focus on fire 6 , and we obtained the following results shown in Figure 8 . Let $d_{f}$ denote the fractal dimension of the footprint, and $d_{f, p}$ the median value of the fractal dimensions of the patches.

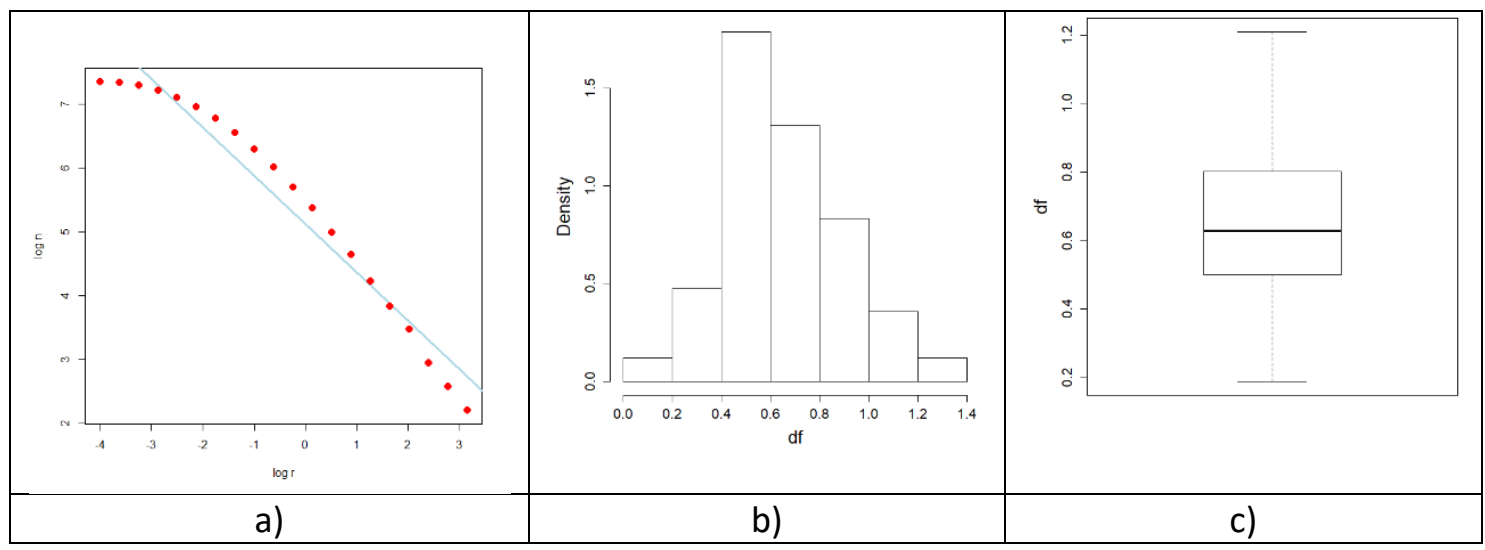

Figure 8: Fractal dimension of the footprint of fire $6(a), d_{f}=1.11$ and distribution of the fractal dimensions of the patches ( $b$ and $c$ ). The median of the patches $d_{f, p}=0.65$ is clearly less than the fractal dimension of the footprint.

Figure 8a shows the fractal dimension as minus the slope of the line between $\log (r)$ and $\log (n)$. Here we find $d_{f}=1.11$ for $\log r$ values above 1 . We note that this is not a monofractal, as the slope deviates from a straight line for lower values of $r$. This makes it difficult to compare the fractal dimensions of the 
footprint with the monofractals as observed for the holes, which have typical distances $\log r=-4$ and $\log$ $r=-2$. Figure $8 \mathrm{~b}$-c show a statistical summary of the fractal dimensions of the holes in the fire 6 footprint. The holes behaved as monofractal objects for $r<0.5 \mathrm{~m}$ and their fractal dimension was below 1.11. Its median value $d_{f, p}=0.68$, as is shown by the boxplot. Similar results were obtained for the second bush fire $\left(d_{f}=1.31, d_{f, p}=0.96\right)$. For the first burn we find $d_{f}=1.01$ and $d_{f, p}=0.84$ and for the second burn we find $d_{f}=1.16$, and $d_{f, p}=0.80$ (see supplementary materials). We notice that the fractal dimensions of the boundaries of the holes are lower than that of the fire. The explanation is that holes are smaller in size and are less affected by stochastic influences from outside. Also, there is no clear difference between a bushfire and a burn.

\subsection{Remote Sensing}

Figure 9 presents results from Normalized Difference Vegetation Index (NDVI) analysis using Landsat 7 ETM (Figure 9). In this figure we observe that after the fire, on 15 February, NDVI dropped dramatically after the fire and is not restored after five months. This agrees with the satellite image on Figure 3, where fire affected area results in darker areas after the fire event, except for the Eastern side of the fire extent where we observe some prominent vegetation in the image of June 2006 that we attribute to agriculture. Therefore we conclude that actual restoration of NDVI values by June 2006 is lower than what is suggested by our analysis. The thin cloud covering a portion of the polygon partially obscures some of the vegetation and has a slight reduction of the NDVI pixel values for bare soil in the fire affected area thus reducing the overall NDVI values, but is not affecting the statistics for the holes. This means that actual reduction of NDVI due to the fire is even larger than that reported in Figure 9 . In contrast to the fire affected area, the NDVI values in the holes do not substantially change. 

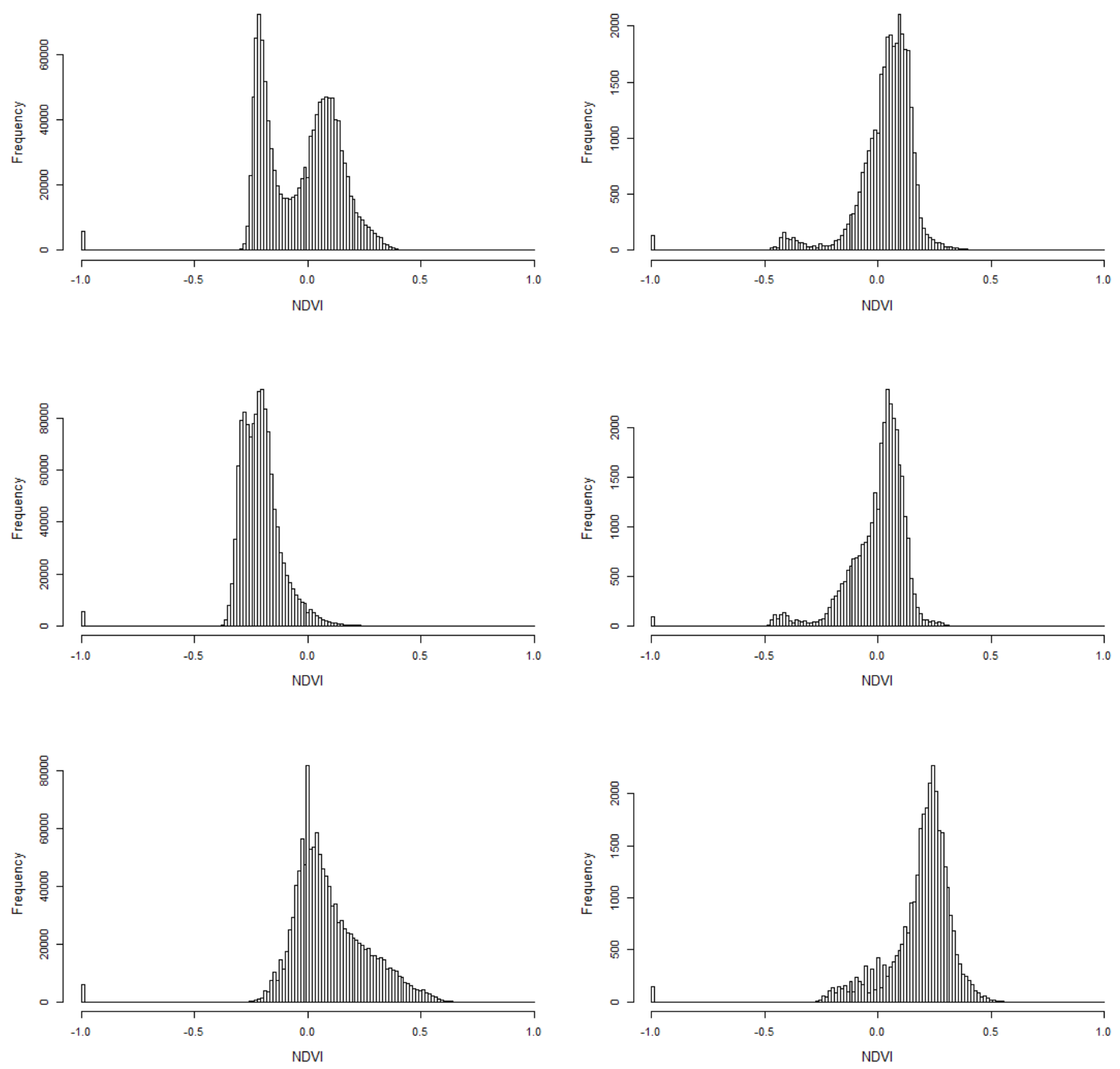

Figure 9: Satellite NDVI (Landsat 7) for bushfire 6 from Figure 3a, from 20 January 2006. Rows: top is before the fire event 29 December 2005; middle is after the fire event, 15 February 2006; bottom is 14 June 2006. Columns: left the area affected by fire, excluding the holes, right: inside the holes, respectively.

\section{Discussion}

This study analyzed patches of vegetation, so called holes, within a forest fire footprint. We used spatial statistical methods to be able to deal with the large amount of data collected in space and time and to quantify the uncertainty associated with their observation and interpretation. Spatial statistics was useful, as the characterization of locations of holes, and their pattern could be quantified. We have done this for a few footprints, but we can see that a more common and standard use could be beneficial. 
We have used the data as they are available in the Victoria fire database. From these data our methodology analyzed the 'holes' using distances from the centre of the fire scar, rather than distances from other fire behavior features, like the ignition point, critical geographic points for wildfire spread, aspect, slope, main wind directions, fuel managed areas (McCarthy et al. 2017). From a fire behavior point of view, one could think it makes more sense to estimate distance from one or some of this features rather than the centre of the perimeter and they would provide additional possibilities for analysis. Those data, how useful as they are, are not generally available and for the spatial statistical analysis the differences are negligible in case of stationarity.

Further work can be done on modeling the fire frontiers, in particular when observations of a high temporal resolution would become available (Hesseln et al. 2010; Katuwal et al. 2016). In this sense the different scales are relevant: from the nationwide level, to the individual forest fire and to the individual hole. Most of the understanding of the forest fire relates to the presence of vegetation and other forms of fuel. We should then better understand where the fire is going and what determines its movement. This could in time lead to more realistic modeling of wildfires in relation to wind pattern analysis (Ziegler et al. 2017, Parsons et al. 2017, Jaafari et al., 2018) and a further development of e.g. the commonly used Phoenix fire propagation model (Tolhurst et al. 2008). We see that this may extend to a good propagation model that also would include underground heat propagation and above ground spread of burning material by the extreme winds around forest fires.

To characterize the status of the holes, we used remote sensing images. It showed large potentials already at the scale that we were using it. In particular characterization of the vegetation vigor in patches may lead to identify sub-areas with a relatively low NDVI that are hence more vulnerable to fires than surrounding areas. In the near future, we expect further developments. A higher resolution, but in particular also a larger frequency of observation, so that individual fires can be monitored and a much better characterization of its behavior can be obtained. We did not further explore the presence of mixed pixels. Mixed pixels obtain contribution from various land cover, on our case this is burnt and unburnt vegetation. They could naturally occur at the boundaries of the holes. Especially smaller holes might be too small to detect as pure pixels and be covered mainly by mixed pixels. Such pixels may be further characterized by soft classification techniques or super-resolution mapping, addressing the severity and the proportion of burnt vegetation.

In a rich and highly diverse landscape as a forest, this can be of interest and should serve as a good direction for future research. At present the potential use of drones is being explored. Because of the combination of fire and smoke, it will be difficult to use those to monitor the frontier of the fire, but we with dedicated use, more immediate observations can be collected. In short, drones may offer finer resolution image and reduce the number of mixed pixels. A further extension of the methodology developed here can be identified into the direction of agricultural areas, which in Victoria occur in the vicinity of the forests. The similar types of land cover make it often difficult to properly investigate the forest from its nearby areas. A critical issue in properly understanding the behavior of forest fires is the fuel connectivity structure of a forest (Nugent et al. 2014). With the current images, we only see the top of the canopy. In the future, it may be possible also to look under the tree (Dubeau et al. 2017, Rappold et al. 2017). Developments in the domain of radar remote sensing may go further into this direction.

We next like to come back to the research motivation as provided in the introduction. First, it is interesting to explore why holes emerge at all (Farmer et al. 2011). Reasons can be manifold, and are difficult to extract from a general spatial observation and pattern analysis. Their potential cuases can 
only be validated on patches for a large range of individual bush fires. Validation with additional information like existing maps and other forms of information is required. That is at this moment outside the coppe of the exploratory nature of this paper. Second, the holes can serve as an agent to regenerate a forest after the burn. We saw from the multitemporal remote sensing image that a change in vegetation appears, that is rapidly harmonizing with its environment. Also here, more analysis is required, in particular focusing on monitoring individual footprints and the role of biodiversity. That, again is outside the scope of this paper, but the indications given by the multitemporal images are promising. Third, holes have been under a severe temperature stress and their composition is most likely affected by the fire around. Also this motivation is difficult to study at this stage, although we have seen that the vigor of vegetation as quantified by the NDVI is slowly recovering. Fourth, little if anything is known about their structure and distribution in space. Here is the major contribution of the paper, as we have clearly seen that the patterns of holes are clustered on small distances and are regular at larger distances. Moreover, the holes are are away from the middle of the footprint. This could also lead to additional research in particular in relation with the history of the fire. Apart from natural and preexisting causes for holes like water bodies, houses and gardens, we may hypothesize that more holes occur close to the furthest extension of the fire, i.e. where the fire extinguished. Most likely this is the place where most activities of extinction took place, where the fire intensity became less and hence vegetation could more easily survive.

The resilience of the forest after the burning is a general point of concern. Using the latest methods in earth observation and spatial statistics may help us to quantify essential elements. So far, we focused mainly on the vegetation as such, but the relations with other occupants of the forest, like animals, water bodies, fungi and in particular also the subsurface are to be further explored. It remains to be investigated how the forest responds to the immense pressure expressed by the heat and the smoke of a forest fire, be it a bushfire or a burn or in terms of the diversity (Zimmer et al. 2015). That clearly goes beyond individual trees, and also includes their interactions and the wider ecological context.

Finally, we would like to mention the use of the results with the interests of the different stakeholders. We will discriminate between fire fighters, forest managers, the local population. We could see clear possibilities with fire fighters, as a dedicated use of remote sensing images and spatial statistics would help to make better predictions and earlier detection of forest fires. Dry spots in the canopy may relate to general drought in the vegetation and hence to a larger vulnerability. Forest managers would benefit from a good modeling and a further extension of the above methods. Their main interest is that a burn remains under control. They could then better decide on the best place and moment to ignite a burn, hence to minimize the risks of increase in intensity, escaping fires and creating mosaic landscape (Hollis et al. 2015). The local population within and at the edge of the forests could be better informed about behavior of the fire, but also on the consequences for their health, either physical by inhaling smoke, being trapped by the fire and severely wounded or killed, or mental health leading to increased fear. This will all come down to fire modelling as it is reported abundantly in the literature. There are variables associated with canopy characteristics (foliage, drought), understory characteristics, weather variables (wind speed and direction) and terrain variables (slope, presence of water bodies). The output of the model should then be a risk indicator, towards each of those variables, and may include risks for biodiversity and animal life. This could serve as an integrated framework on fire modelling in which the analysis of the holes, shows relevance and novelty for bushfire studies. As we read from Department of Environment, Land, Water and Planning (2015), 



\section{Conclusions}

We conclude that holes are inherent in bushfires and burns. They deserve to be studied, as on the one hand they have been under high pressure and on the other hand are part of the new vegetation after the forest fire. The statistical analysis was informative as it showed that the number of holes does not follow a commonly used distribution: neither the lognormal nor the Poisson distribution properly coincided with the observed numbers of holes, whereas the size of holes followed a log-Gaussian distribution. The pattern of holes could have a clear inhomogeneity, with clustering occurring at small distances, possibly as an effect of fire extinction activities, and we observed regularity at larger distances. The fractal dimension of hole boundaries is generally smaller than that of the boundary of the fire. The NDVI of the holes was highly affected by the forest fires, and only very slowly (periods at least longer than six months) are needed to more fully recover.

\section{Acknowledgment}

This paper has been published following a stay of one of us (A. Stein) at the University of Melbourne. The authors is grateful to the Marie-Curie GeoSafe program to allow this trip. We are further very grateful to Dr. Karen Reinke who supported us in our research.

\section{References}

Anscombe, F.J. (1950). Sampling theory of the negative binomial and logarithmic series distributions Biometrika, 37, 358-382.

Baddeley, A., Rubak, E. \& Turner, R. (2016). Spatial point patterns. Methodology and applications in R. CRC Press, Boca Raton.

Copernicus (2018). The Copernicus Global Land Service. https://land.copernicus.eu/global/products/BA. Last accessed: April $4^{\text {th }}, 2018$.

Department of Environment, Land, Water and Planning (2015). Strategic bushfire management plan: West Central. Department of Environment, Land, Water and Planning, State Government of Victoria.

Dubeau, P., King, D.J.; Unbushe, D.G. \& Rebelo L.M. (2017). Mapping the Dabus Wetlands, Ethiopia, Using Random Forest Classification of Landsat, PALSAR and Topographic Data. Remote Sensing 9 (10), Article Number: 1056

Duff, T.J. \& Tolhurst, K.G. (2015). Operational wildfire suppression modelling: a review evaluating development, state of the art and future directions. International Journal of Wildland Fire, 24 (6), 735748.

EFFIS (2018). The European Forest Fire Information Service. http://effis.jrc.ec.europa.eu/. Last accessed: April $4^{\text {th }} 2018$.

Farmer, E., Reinke, K.J, and Jones, S.D. 2011. A current perspective on Australian woody vegetation maps and implications for small remnant patches. Journal of Spatial Science 56 (2), 223-240 
Gupta, V., Reinke, K., Jones, S., Wallace, L. \& Holden, L. (2015). Assessing Metrics for Estimating Fire Induced Change in the Forest Understorey Structure Using Terrestrial Laser Scanning. Remote Sensing 7 (6), $8180-8201$.

Hally, B., Wallace, L., Reinke, K. \& Jones, S. (2017). A Broad-Area Method for Estimation of Upwelling Medium Wave Infrared for Fire Detection. Remote Sensing, 9, 167

Hering, A.S., Bell, C.L. \& Genton, M.G. (2009). Modeling spatiotemporal wildfire ignition point patterns. Environmental and Ecological Statistics, 16 (2), 225-250.

Hesseln, H., Amacher, G.S. \& Deskins, A. (2010). Economic analysis of geospatial technologies for wildfire suppression. International Journal of Wildland Fire 19 (4), 468-477.

Hollis, J.J. Gould, J.S., Cruz, M.G. \& McCaw, W.L. (2015). Framework for an Australian fuel classification to support bushfire management, Australian Forestry, 78 (1), 1-17.

Jaafari, A., Zenner, E.K. \& Thai Pham, B. (2018). Wildfire spatial pattern analysis in the Zagros Mountains, Iran: A comparative study of decision tree based classifiers. Ecological Informatics 43, 200-211.

Katuwal, H., Calkin, D. E. \& Hand, M.S. (2016), Production and efficiency of large wildland fire suppression effort: A stochastic frontier analysis. Journal of Environmental Management, 166, 227-236.

Keeley, J.E. (2009). Fire intensity, fire severity and burn severity: a brief review and suggested usage. International Journal of Wildland Fire, 18, 116-126.

Massé J.-C. \& Theodorescu R. (2005). Neyman type A distribution revisited. Statistica Neerlandica, 59, 206-213.

McCarthy, G., Moon, K. \& Smith, L. (2017). Mapping severity and fire extent in forest in Victoria for ecological and fuel outcomes. Ecological Management \& Restoration, 18, $54-65$.

Mitchell, S., Jones, S., Reinke, K., Lorenz, E. \& Reulke, R. (2016). Assessing the utility of the TET-1 hotspot detection and characterization algorithm for determining wildfire size and temperature. International Journal of Remote Sensing, 37 (20), 4731-4747.

Nangendo, G., Stein, A., ter Steege, H. \& Bongers, F. (2005). Changes in woody plant composition of three vegetation types exposed to a similar fire regime for over 46 years. Forest Ecology and Management, 217 (2-3), 351-364.

Nugent, D.T., Leonard, S.W. J. \& Clarke, M.F. (2014). Interactions between the superb lyrebird (Menura novaehollandiae) and fire in south-eastern Australia. Wildlife Research 41 (3), 203-211.

Parsons, R. A., Linn, R.R.; Pimont, F., Hoffman, C., Sauer, J. Winterkamp, J., Sieg, C.H. \& Jolly, W.M. (2017). Numerical Investigation of Aggregated Fuel Spatial Pattern Impacts on Fire Behavior. LAND 6 (2), Article Number: 43.

Pausas, J.G. \& Keeley, J.E. (2009). A burning story: the role of fire in the history of life. Bioscience, 59, 593 $-601$. 
Penman, T.D., Collins, L., Price, O.F., Bradstock, R.A., Metcalf, S. \& Chong, D.M.O. (2013). Examining the relative effects of fire weather, suppression and fuel treatment on fire behaviour - A simulation study. Journal of Environmental Management, 131, 325-333.

Penman, T.D., Kavanagh, R.P. Binns, D.L. \& Melick, D.R. (2007). Patchiness of prescribed burns in dry sclerophyll eucalypt forests in South-eastern Australia. Forest Ecology and Management, 252, 24-32.

Quintano, C., Fernández-Manso, A., Stein, A. \& Bijker, W. (2011). Estimation of area burned by forest fires in Mediterranean countries : a remote sensing data mining perspective. Forest Ecology and Management, 262 (8), 1597-1607.

Quintano, C., Stein, A. \& Bijker, W. (2010). Pattern validation for MODIS image mining of burned area objects. International Journal of Remote Sensing, 31 (12) , 3065-3087.

Rappold, A.G., Reyes, J., Pouliot, G., Cascio, W.E. \& Diaz-Sanches, D. (2017). Community Vulnerability to Health Impacts of Wildland Fire Smoke Exposure. Environmental Science \& Technology 51, (12), 66746682

Ripley, B.D. (1977). Modelling spaytial patgterns (with discussion). Journal of the Royal Statistical Society, Serries B, 39, $172-212$.

Tolhurst, K., Shields, B. \& Chong, D. (2008). Phoenix: development and application of a bushfire risk management tool. The Australian Journal of Emergency Management, 23 (4), 47- 54.

Turner, R. (2009). Point patterns of forest fire locations. Environmental and Ecological Statistics 16 (2), 197-223.

Umamaheshwaran, R., Bijker, W. \& Stein, A. (2007). Image mining for modeling of forest fires from meteosat images. IEEE Transactions on Geoscience and Remote Sensing, 45 (1), 246-253.

Victoria (2018). The Victoria bushfire database. https://www.data.vic.gov.au/data/dataset/fire-historyrecords-of-fires-primarily-on-public-land. Last accessed: April $4^{\text {th }} 2018$.

Wallace, L., Gupta, V., Reinke, K. \& Jones, S. (2016). An Assessment of Pre- and Post Fire Near Surface Fuel Hazard in an Australian Dry Sclerophyll Forest Using Point Cloud Data Captured Using a Terrestrial Laser Scanner. Remote Sensing 8 (8):679.

Wotton, B.M. \& Martell, D.L. (2005) A lightning fire occurrence model for Ontario. Canadian Journal of Forest Research 35(6), 1389-1401.

Ziegler, J.P., Hoffman, C., Battaglia, M. \& Mell, W. (2017) Spatially explicit measurements of forest structure and fire behavior following restoration treatments in dry forests. Forest Ecology and Management, 386, 1-12.

Zimmer, H.C., Auld, T.D., Hughes, L. (2015). Fuel flammability and fire responses of juvenile canopy species in a temperate rainforest ecosystem. International Journal of Wildland Fire, 24 (3), 349-360. 



\section{Supplementary materials}

Intensity and K functions for fire 187 (bushfire).

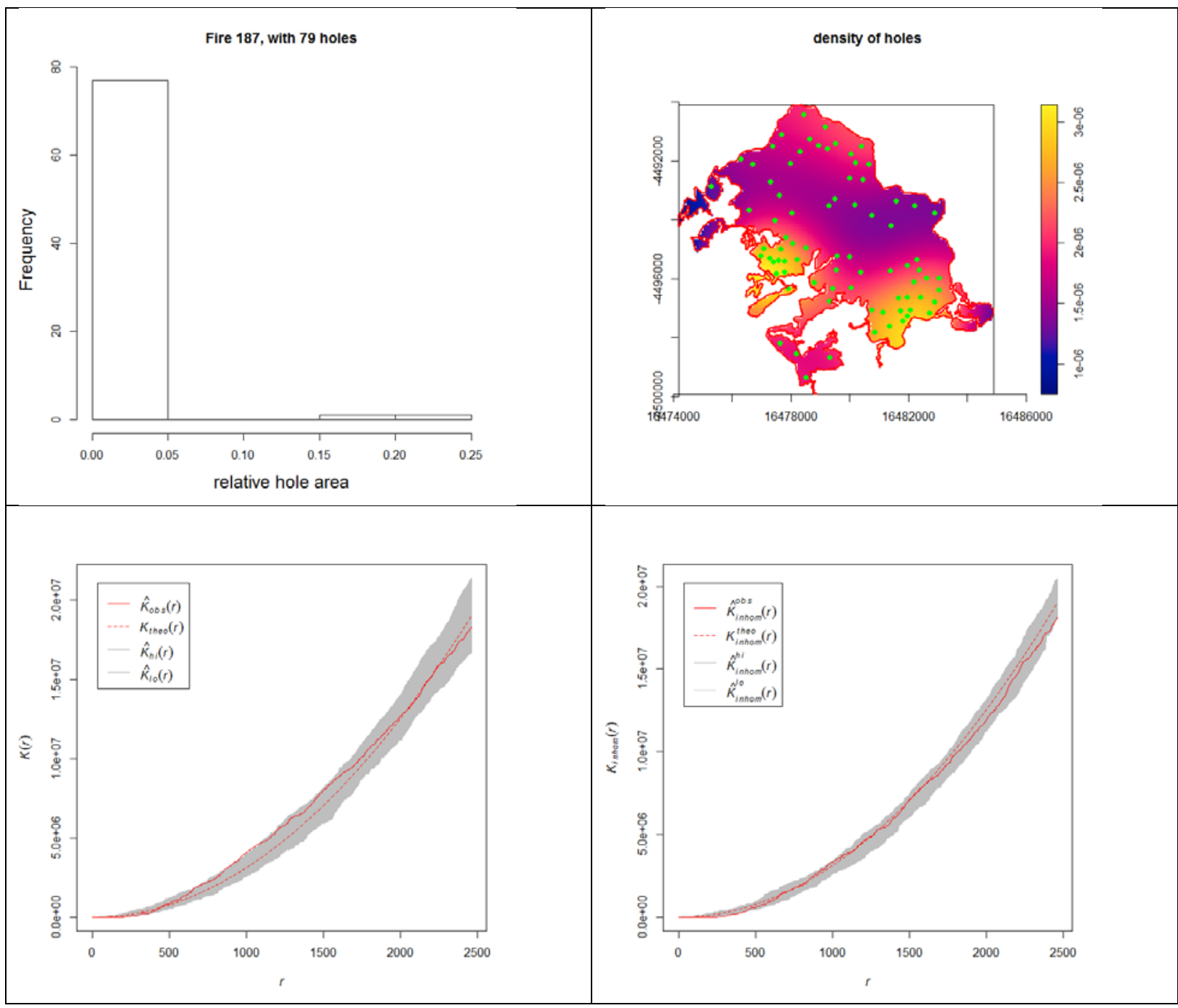


Intensity and $\mathrm{K}$ function for fire 73 (burn).
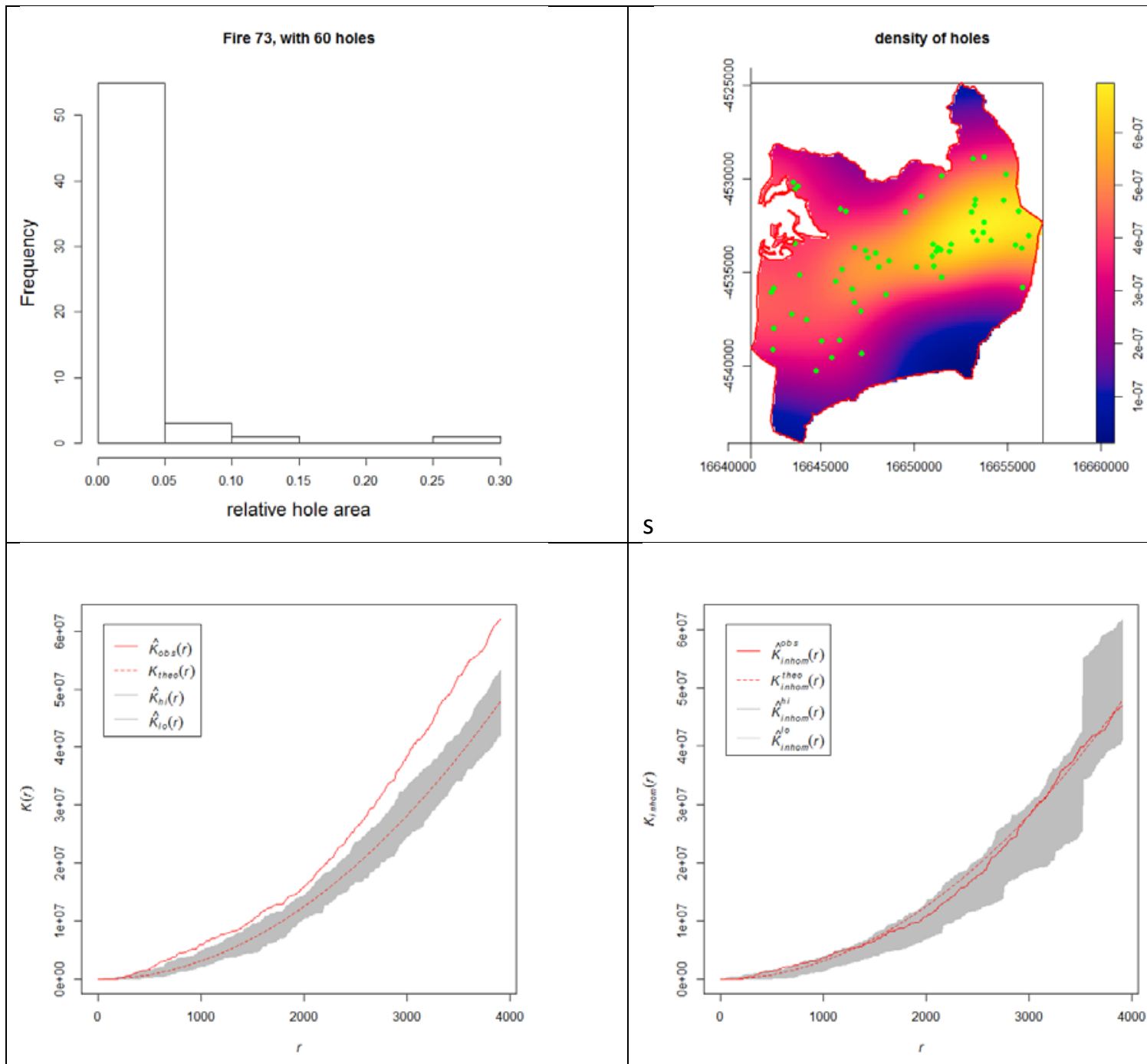

S

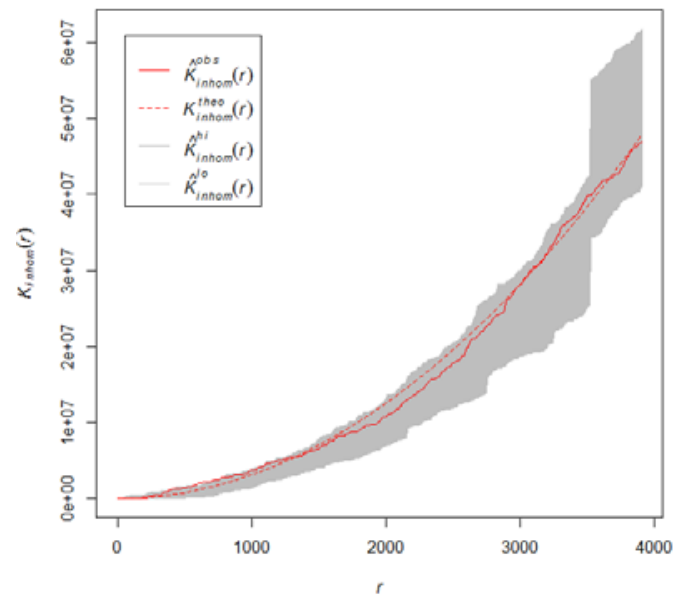




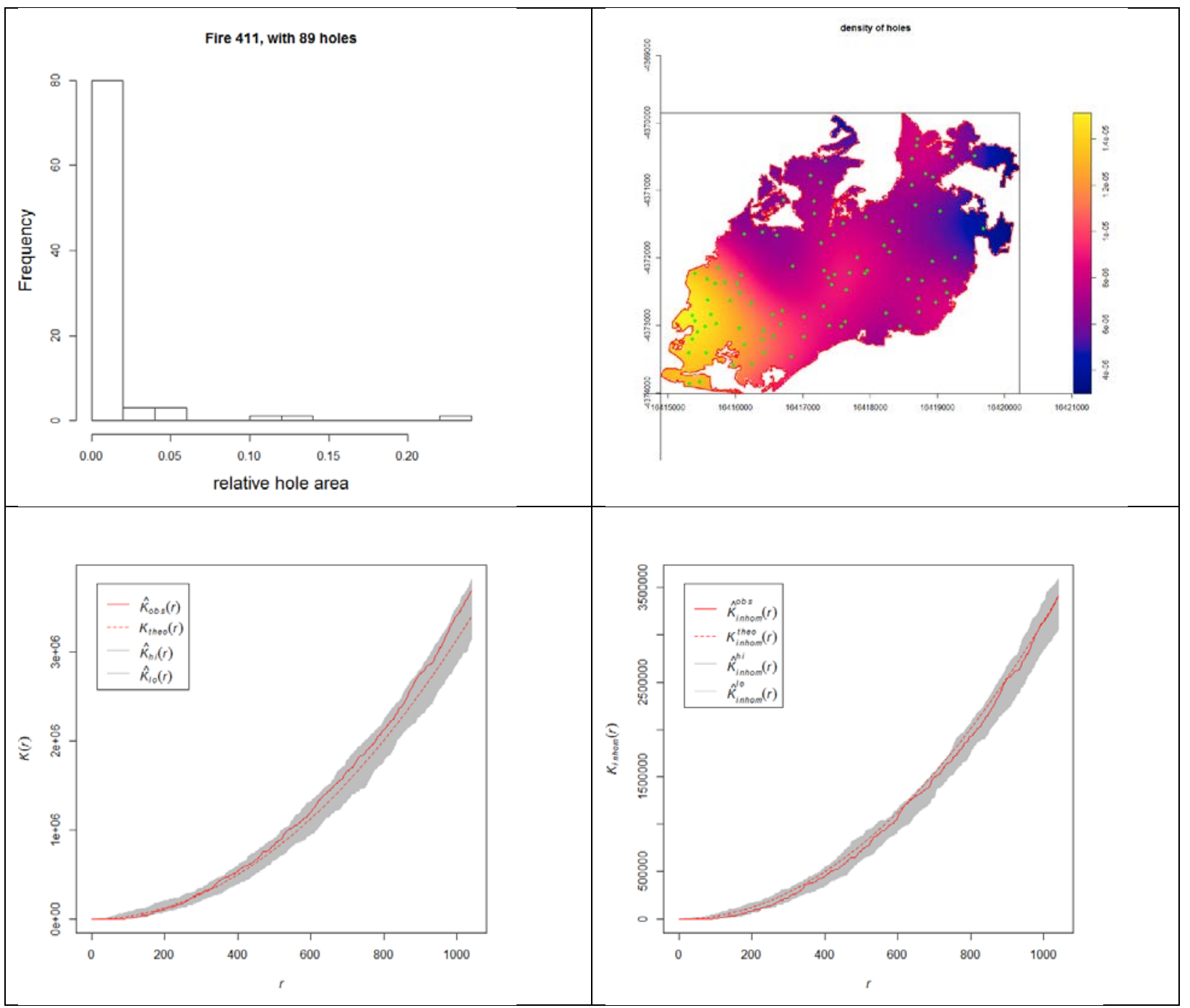




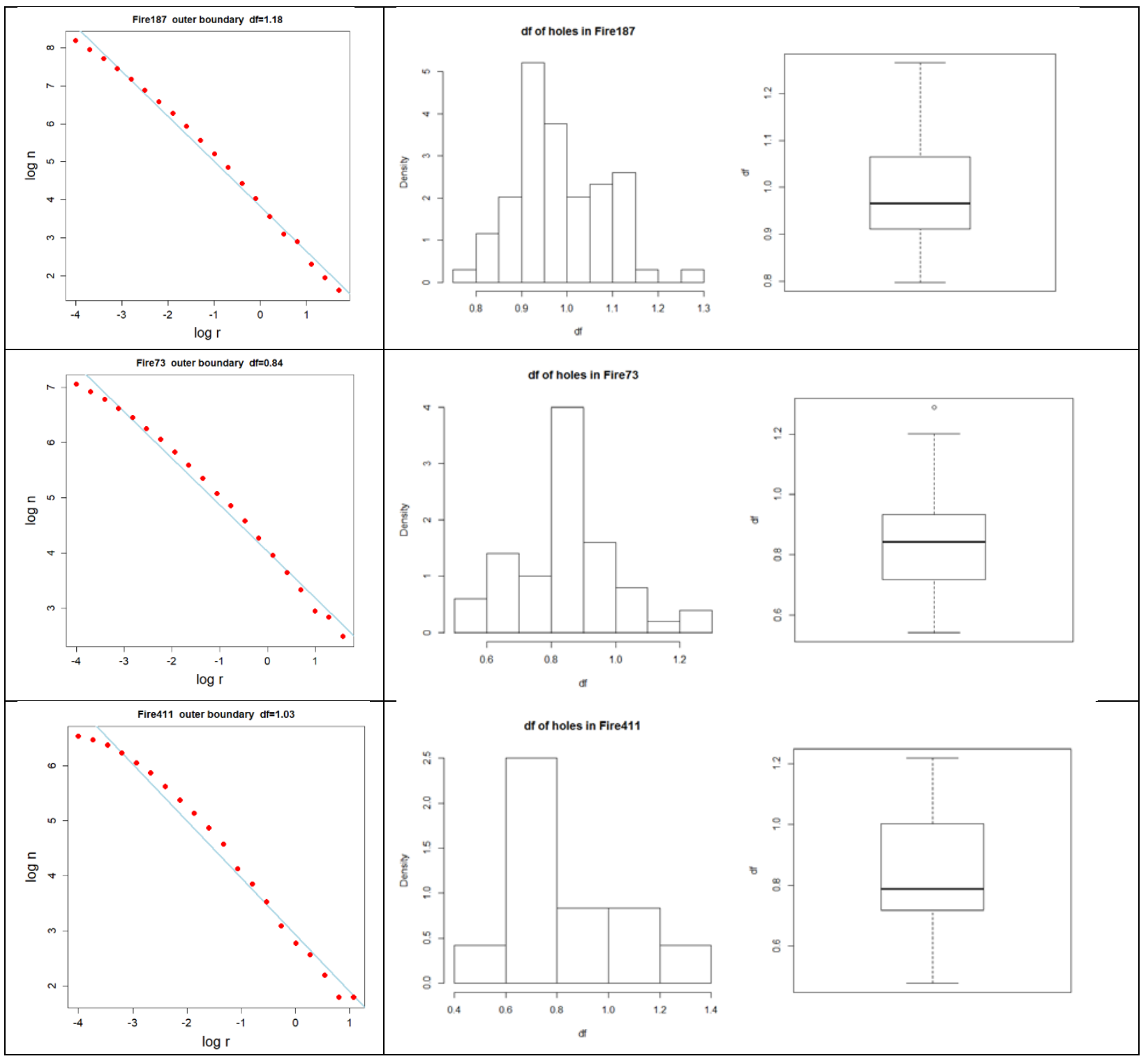

